
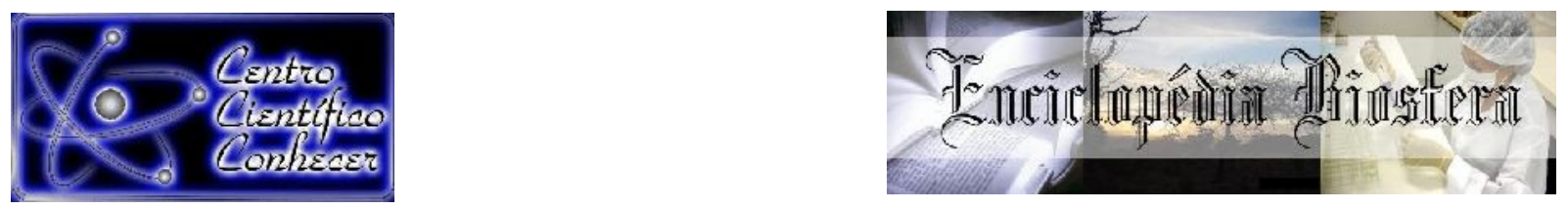

\title{
A CÓRNEA E AS CERATITES ULCERATIVAS EM CÃES: UMA REVISÃO DA ANATOMIA, ETIOPATOGENIA E DIAGNÓSTICO
}

\author{
Thaissa Vaz Lobo ${ }^{1}$, Anna Rosa Martins Sant'Anna ${ }^{2}$, Andre Ribeiro Fayad ${ }^{1}$, Aline Maria \\ Vasconcelos Lima ${ }^{3}$ \\ ${ }^{1}$ Mestranda(o) do Programa de Pós-graduação em Ciência Animal (PPGCA), da Escola \\ de Veterinária e Zootecnia (EVZ), da Universidade Federal de Goiás (UFG), Goiânia- \\ GO. \\ ${ }^{2}$ Graduanda do curso de Medicina Veterinária da Escola de Veterinária e Zootecnia \\ (EVZ), da Universidade Federal de Goiás (UFG), Goiânia-GO. \\ ${ }^{3}$ Doutora em Ciência Animal pela Escola de Veterinária e Zootecnia (EVZ), da \\ Universidade Federal de Goiás (UFG); Professora Adjunta da Escola de Veterinária e \\ Zootecnia (EVZ), da Universidade Federal de Goiás (UFG), Goiânia-GO. \\ aline_lima@ufg.br
}

\section{Recebido em: 15/05/2021 - Aprovado em: 15/06/2021 - Publicado em: 30/06/2021 DOI: 10.18677/EnciBio_2021B2}

\begin{abstract}
RESUMO
A córnea é um tecido da túnica fibrosa do bulbo ocular, e suas características morfológicas a tornam o principal meio refrativo do olho, contribuindo sobremaneira com a acuidade visual. Por esse motivo as doenças da córnea ganham grande relevância na oftalmologia e, dentre as ceratopatias mais comuns na clínica de cães, a ceratite ulcerativa se destaca, sendo considerada como uma emergência oftálmica e uma causa de cegueira. As causas da ceratite ulcerativa em cães são variadas, mas ganham destaque os traumas e os distúrbios do filme lacrimal; sendo os cães braquicefálicos os mais comumente acometidos. A partir da desepitelização corneana, a ação de metaloproteinases endógenas e exógenas contribuem para a progressão da enfermidade, a qual se manifesta por meio de sinais clínicos como hiperemia conjuntival, blefarospasmo, alteração da coloração e da curvatura corneana. O diagnóstico se baseia na identificação e na classificação da ceratite ulcerativa, assim como na causa base do desenvolvimento da doença. O conhecimento dos aspectos básicos envolvidos com o desenvolvimento e diagnóstico das ceratites ulcerativas em cães possibilita ao médico veterinário a tomada de decisões terapêuticas mais efetivas para o controle da doença. Diante do exposto, o objetivo desta revisão foi descrever os aspectos morfológicos da córnea e apresentar os elementos envolvidos com a epidemiologia, etiologia e fisiopatogenia das ceratites ulcerativas em cães; assim como as técnicas mais comumente utilizadas para o diagnóstico e classificação desta enfermidade.
\end{abstract}

PALAVRAS-CHAVE: Cão, corneana, patogênese, úlcera. 


\title{
CORNEA AND ULCERATIVE KERATITIS IN DOGS: AN ANATOMY, ETIOPATOGENY AND DIAGNOSIS REVIEW
}

\begin{abstract}
Cornea is a component of the eye bulb fibrous tunic and its morphological characteristics make it the main refractive tissue of the eye, contributing to the visual acuity. For this reason, corneal diseases have great impact in veterinary ophthalmology. Among the most common keratopathies in dogs, ulcerative keratitis has an important role, because it is considered as an ophthalmic emergency and it is a cause of blindness. Ulcerative keratitis has multiple causes and the most common are trauma and lacrimal film disorders. Brachycephalic dogs are the most affected breeds. From corneal ulceration, the action of endogenous and exogenous metalloproteinases contributes to the progression of the disease, which manifests itself through clinical signs of conjunctival hyperemia, blepharospasm, edema, and alterations in the corneal curvature. The diagnosis is based on the identification and classification of the ulcerative keratitis, as well as the underlying cause of the disease development. The knowledge of basic aspects involved with the development and diagnosis of ulcerative keratitis in dogs enables the veterinarian to make effective therapeutic decisions to control the illness. Therefore, the aim of this review is to describe the morphological aspects of the cornea and present the elements involved with epidemiology, etiology and pathophysiology of ulcerative keratitis in dogs; as well as the most commonly techniques used to diagnose and classify it.
\end{abstract}

KEYWORDS: dog, corneal, pathogenesis, ulcer

\section{INTRODUÇÃO}

A córnea é a porção mais externa do segmento anterior do bulbo ocular dos cães, é a superfície de refração óptica mais importante do olho, e sua transparência é essencial para a qualidade da visão. A córnea é uma estrutura avascular, translúcida, composta histologicamente pelo epitélio, estroma, membrana Descemet e endotélio (MAZZI; DIAS, 2018; MEEKINS, 2021).

A ceratite ulcerativa, também denominada úlcera de córnea, é uma das oftalmopatias mais comuns em cães, estando muito presente na rotina clínica e existem diversas causas que podem desencadear essa afecção. A úlcera de córnea é considerada uma urgência oftalmológica, e o diagnóstico e tratamento precoces são fundamentais para que a mesma não evolua para perfuração ocular, que pode levar a déficit visual e até mesmo à inviabilidade do bulbo ocular decorrente de endoftalmite, glaucoma ou Pthisis bulbi (SLATTER, 2015; O'NEILL et al., 2017; MONTEIRO et al., 2018; GOGOVA et al., 2020; MEEKINS, 2021).

A úlcera de córnea está presente quando há uma quebra da barreira epitelial, que expõe o estroma corneano subjacente. Em decorrência da lesão, os cães apresentam sinais clínicos como lacrimejamento, blefaroespasmo, fotofobia, hiperemia conjuntival, edema de córnea e miose (MAGGS et al., 2017).

O diagnóstico da ceratite ulcerativa é feito com base nos sinais clínicos e na retenção do colírio de fluoresceína pelo estroma corneano. A classificação das úlceras é essencial para o planejamento terapêutico e é feita de acordo com a profundidade da lesão e com a presença ou ausência de degradação do colágeno estromal. Na maioria ENCICLOPÉDIA BIOSFERA, Centro Científico Conhecer - Jandaia-GO, v.18 n.36; p. 18 2021 
dos casos, apesar de causarem bastante desconforto, as úlceras superficiais cicatrizam rapidamente, com formação mínima de cicatriz. No entanto, úlceras profundas podem levar à formação de cicatriz com variados graus de opacidade e extensão, culminando até mesmo com a perda da visão (FEATHERSTONE; CHRISTINE, 2021).

O conhecimento dos aspectos básicos envolvidos com o desenvolvimento das úlceras corneanas em cães possibilita ao médico veterinário a tomada de decisões terapêuticas mais efetivas para o controle da doença. Diante do exposto, o objetivo desta revisão foi descrever os aspectos morfológicos da córnea e apresentar os elementos envolvidos com a epidemiologia, etiologia e fisiopatogenia das ceratites ulcerativas em cães; assim como as técnicas mais comumente utilizadas para o diagnóstico e classificação desta enfermidade.

\section{Morfofisiologia da córnea do cão}

O bulbo ocular dos cães é formado pelas túnicas fibrosa, vascular e neural. A túnica fibrosa é composta pela córnea, limbo e esclera, e é responsável pela forma e proteção do bulbo ocular. A túnica vascular ou média é formada pelo trato uveal, que compreende íris, corpo ciliar e coroide, e está envolvida com a nutrição do bulbo ocular e a regulação do formato da lente e da pupila. A túnica mais interna do bulbo ocular é a neural, composta pela retina e papila óptica, e está relacionada com a neurofisiologia da visão (MEEKINS, 2021) (Figura 1).

FIGURA 1. Desenho esquemático da anatomia do bulbo ocular de cão, ilustrando as estruturas que compõem a túnica fibrosa (córnea, limbo e esclera), a túnica vascular (íris, corpo ciliar e coroide) e a túnica fibrosa (retina); assim como a câmara anterior (CA), câmara posterior (CP) e câmara vítrea (CV).

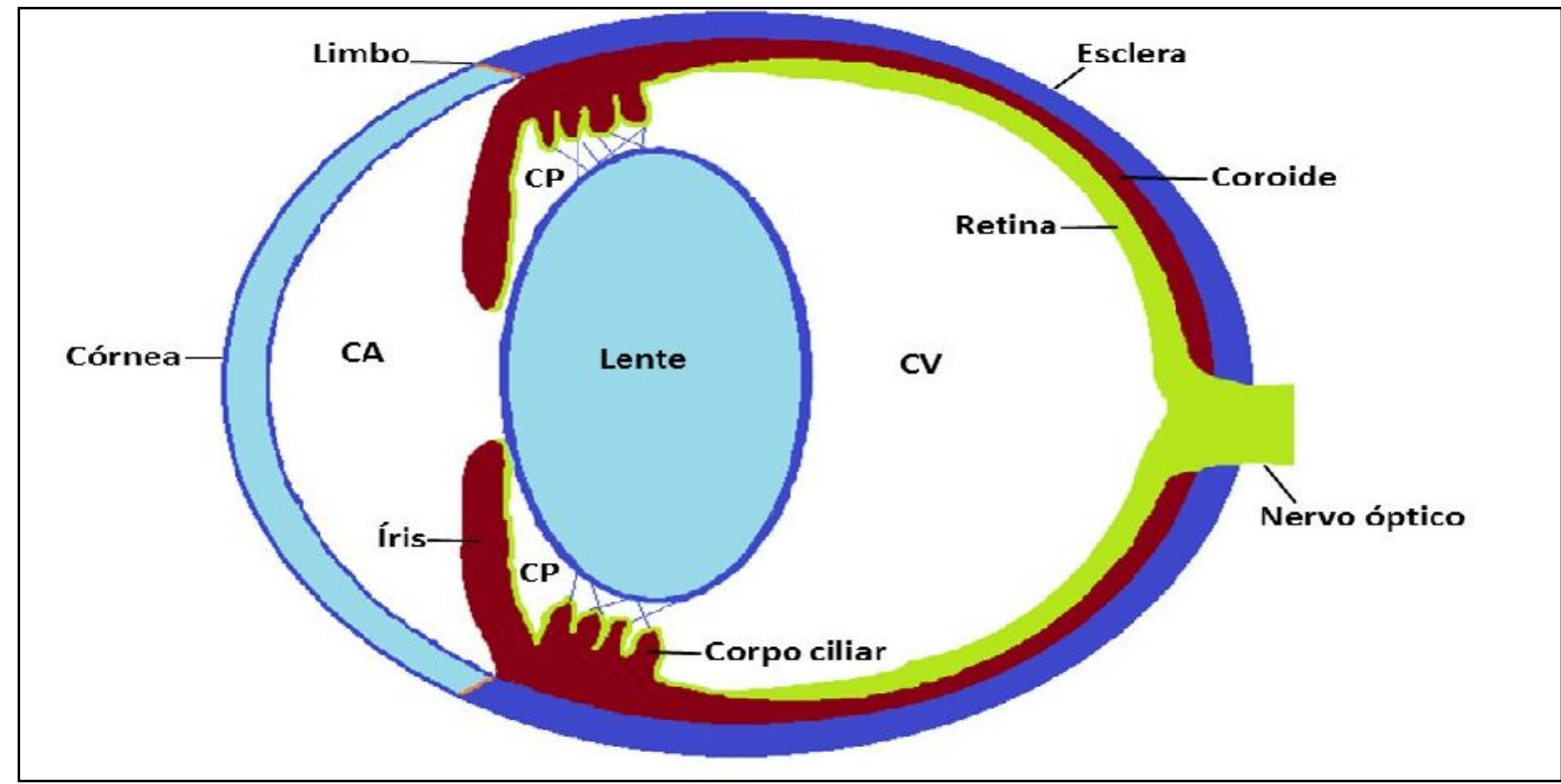

Fonte: Arquivo pessoal da autora Aline Maria Vasconcelos Lima (2021).

$\mathrm{O}$ bulbo ocular ainda pode ser dividido em segmento anterior e posterior. $\mathrm{O}$ segmento anterior é preenchido por humor aquoso. Fazem parte dele, a câmara anterior, espaço localizado entre a córnea e a íris; e câmara posterior, situada entre a ENCICLOPÉDIA BIOSFERA, Centro Científico Conhecer - Jandaia-GO, v.18 n.36; p. 19 
íris e a lente. A câmara vítrea se encontra entre lente e retina, e é preenchida pelo corpo vítreo, e faz parte do segmento posterior do bulbo ocular (SLATTER, 2005).

A córnea dos cães encontra-se na porção anterior e no eixo central da túnica fibrosa e relaciona-se perifericamente com a esclera por meio da zona de transição denominada limbo corneoescleral. O diâmetro da córnea do cão varia entre $12,5 \mathrm{~mm}$ e $17 \mathrm{~mm}$ e a espessura entre $0,6 \mathrm{~mm}$ a $0,95 \mathrm{~mm}$, sendo mais espessa na periferia em relação ao centro (MEEKINS, 2021). A transparência é uma característica da córnea e ocorre devido à organização das fibrilas colágenas do estroma corneano, à ausência de vasos e pigmentos, e ao estado constante de deturgescência (MAGGS, 2017).

A córnea é suprida por nervos sensoriais que penetram no estroma junto ao limbo, e se ramificam em direção à área central, culminando em terminações nervosas livres (GALERA et al., 2009). A nutrição do tecido corneano se dá por intercâmbio do oxigênio e nutrientes transportados pelo filme lacrimal, humor aquoso e capilares do limbo (HERRERA, 2008).

A principal função da córnea é a de refração dos raios luminosos e a de barreira entre o meio externo e as estruturas intraoculares (MEEKINS, 2021). A córnea atua como uma lente convergente, responsável por $70 \%$ e $80 \%$ do poder dióptrico do olho humano e dos animais domésticos, respectivamente (ANDRADE, 2020). Outra função da córnea é, em conjunto com a esclera, conservar a forma do bulbo ocular e manter a pressão intraocular, o que é imperativo para um sistema visual funcional (GUM et al., 2021).

Histologicamente, a córnea do cão é dividida em quatro camadas: epitélio, estroma, membrana de Descemet e endotélio. O filme lacrimal é considerado funcionalmente a camada mais externa da córnea, contudo não é identificado em cortes histológicos (SLATTER, 2005). (Figura 2).

FIGURA 2. Desenho esquemático das camadas histológicas da córnea do cão, ilustrando o epitélio, estroma, membrana de Descemet e endotélio.

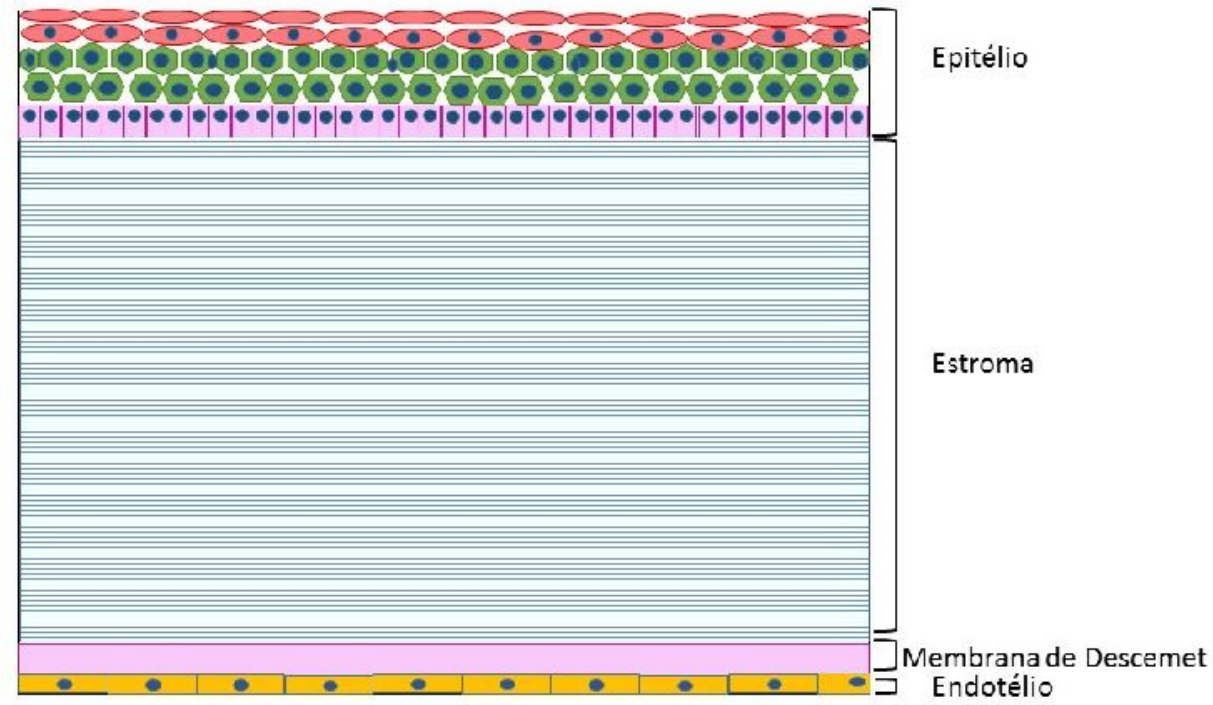

Fonte: Arquivo pessoal da autora Aline Maria Vasconcelos Lima (2021). 


\section{- Filme lacrimal pré-corneano}

O filme lacrimal pré-corneano (FLP) é um composto trilaminar formado por uma camada lipídica (externa), uma camada aquosa (intermediária) e uma camada mucosa (interna). A camada lipídica é produzida pelas glândulas de Meibômio e de Zeiss, localizadas nas pálpebras, e é composta por substância oleosa e fosfolipídeos. A camada aquosa é produzida pelas glândulas lacrimais orbitária, da terceira pálpebra e acessórias, é formada predominantemente por $98 \%$ de água e aproximadamente $2 \%$ de sólidos, constituídos por proteínas, sais inorgânicos, glicose, ureia e glicoproteínas. A camada mucosa é produzida pelas células caliciformes conjuntivais e é composta por glicoproteínas e pelo glicocálix, que está associado às microvilosidades presentes no epitélio corneano (SLATTER, 2005; MEEKINS, 2021).

Dentre as funções do FLP destacam-se a contribuição para a homogeneidade e transparência da superfície corneana, para a lubrificação da superfície ocular, para a nutrição da córnea; e para a resposta imune local (MILLER, 2017). Quaisquer alterações na produção e secreção dos componentes do FLP levam à sua instabilidade e ao comprometimento da superfície ocular e da visão (SLATTER, 2005).

\section{- Epitélio corneano}

O epitélio da córnea do cão é do tipo estratificado escamoso não queratinizado, tem aproximadamente 25 a $40 \mathrm{~m}$ de espessura e é formado por uma monocamada de células basais, duas ou três camadas de células aladas e outras duas a três camadas de células escamosas não queratinizadas (MILLER, 2017). Abaixo do epitélio está a membrana basal, na qual as células basais estão firmemente aderidas por hemidesmossomos, fibrilas colágenas de ancoragem do tipo IV, VI e VII; laminina, hialuronato e fibronectina (MEEKINS, 2021).

As células basais são células colunares, com base achatada e ápice em cúpula. Elas se mantêm justapostas e, como resultado, os núcleos, que estão localizados na região apical, estão frequentemente dispostos em duas ou mais camadas alternadas. É na camada de células basais que ocorre a mitose para a formação das camadas mais superficiais do epitélio corneano. À medida que as células basais se dividem, as células filhas são forçadas em direção à superfície e vão se diferenciando em células aladas, as quais, por sua vez, se diferenciam em células escamosas. As células escamosas gradualmente vão perdendo suas organelas e as mais superficiais se desprendem naturalmente do epitélio (SLATTER, 2005; MAGGS, 2017).

As células aladas são agrupamentos de células poligonais e formam uma zona de transição entre células colunares basais e as células escamosas (MEEKINS, 2021). A camada de células escamosas superficiais é composta por células achatadas e poligonais. Nesta camada, há células em processo de descamação e há células que contém microvilos e micropregas, que são inúmeras projeções visíveis à microscopia eletrônica. A função destas microprojeções é controversa, mas foi postulado que elas sustentam ou estabilizam o filme lacrimal pré-corneano na superfície corneana (MEEKINS, 2021). 
O epitélio é altamente inervado por nervos sensoriais, sendo um dos tecidos mais sensíveis do organismo, servindo como função protetora. Os nervos ciliares longos (derivados da divisão oftálmica do nervo trigêmeo) ramificam-se dentro do estroma anterior e do epitélio, onde as terminações nervosas tornam-se desmielinizadas (MEEKINS, 2021).

\section{- Estroma corneano}

O estroma compreende aproximadamente $90 \%$ da espessura total da córnea, e tem em torno de 0,5mm a 0,6mm. É constituído por $75 \%$ a $85 \%$ de água, bem como por feixes de fibras de colágeno, substância fundamental, ceratócitos, linfócitos, polimorfonucleares e macrófagos (SLATTER, 2005; MAGGS et al., 2017; KIERSZENBAUM; TRES., 2019). Os ceratócitos são fibroblastos modificados e especializados na formação e manutenção das lamelas de colágeno e da matriz extracelular. A matriz extracelular é um complexo que contém glicoproteínas (TURNER, 2010), sendo rica em proteoglicanos de sulfato de condroitina e queratan sulfato (KIERSZENBAUM; TRES, 2019). A grande quantidade de glicosaminoglicanos proporciona uma característica hidrofílica ao estroma corneano (KIERSZENBAUM; TRES, 2019).

Todas as fibrilas que compõem uma lamela são paralelas entre si, mas há uma grande variação de direções entre as lamelas (SLATTER, 2005; LIN; PETERSENJONES, 2007; WHITLEY; HAMOR, 2021). O entrelaçamento e a obliquidade em relação à superfície são maiores no caso das lamelas anteriores e esse arranjo, organizado em forma de rede, torna o estroma resistente a deformações e traumas (KIERSZENBAUM; TRES., 2019). O espaçamento regular das fibrilas estromais constitui um importante fator na manutenção da transparência da córnea, possibilitando ainda a distinção do colágeno do tecido cicatricial e da esclera (MAGGS et al., 2017).

Dos cinco tipos de colágeno que constituem o estroma corneano, os tipos I e V são os mais comuns, e estão relacionados às fibrilas. Já o colágeno tipo VI, está apenas associado à matriz interfibrilar e parece estar implicado nas interações célulamatriz, que são importantes durante o desenvolvimento e a reparação estromal (MEEKINS, 2021).

Embora $75 \%$ a $85 \%$ do estroma seja composto por água, considera-se que este tecido esteja em estado relativo de desidratação, considerando sua grande afinidade pela água em função dos glicosaminoglicanos. Este estado relativo de desidratação, também chamado de deturgescência, depende de muitos fatores. A integridade anatômica do epitélio e endotélio promove barreira física contra o influxo do fluido lacrimal e humor aquoso, respectivamente. Também, a atividade de bombas como a $\mathrm{Na}^{+} / \mathrm{K}^{+}$ATPase e anidrase carbônica possibilitam que as células do epitélio e principalmente do endotélio removam água do estroma corneano, por meio da movimentação de íons $\mathrm{Na}^{+}$e $\mathrm{Ca}^{+2}$ em direção ao fluido lacrimal e ao humor aquoso (WHITLEY; HAMOR, 2021).

\section{Membrana de Descemet e endotélio corneano}

A membrana de Descemet é a membrana basal secretada pelo endotélio corneano, composta por finas fibrilas de colágeno com propriedades elásticas. Estas 
fibrilas podem se romper em situações de distensão do bulbo ocular ou de lesões penetrantes (MAGGS et al., 2017; MURPHY; GUTIERREZ, 2019; MEEKINS, 2021). Por ser secretada de forma constante pelas células endoteliais ao longo da vida, a membrana de Descemet aumenta em espessura com a idade (MAGGS et al., 2017), sendo uma das membranas basais mais espessas do corpo, variando de $5 \mathrm{~m}$ a $10 \mathrm{~m}$ de espessura (KIERSZENBAUM; TRES., 2019).

O endotélio, também chamado de epitélio posterior, é formado por uma camada unicelular, reveste posteriormente a córnea e anteriormente a câmara anterior. Em razão da alta atividade metabólica, as células endoteliais contêm numerosas mitocôndrias e retículo endoplasmático liso e rugoso (MEEKINS, 2021).

O endotélio recebe a maior parte do oxigênio por meio do humor aquoso, ao passo que as demais camadas da córnea recebem principalmente o oxigênio proveniente da atmosfera, dos capilares do limbo e da conjuntiva. As células endoteliais são as grandes responsáveis pela deturgescência do estroma corneano devido, principalmente, à ação de bombas de $\mathrm{Na}^{+} / \mathrm{K}^{+}$ATPase (TURNER, 2010). O estado de desidratação relativa é importante para manutenção da transparência da córnea (KIERSZENBAUM; TRES, 2019).

Quando ocorre perda de $50 \%$ da função das células endoteliais, as células remanescentes não são suficientes para a manutenção da deturgescência estromal, e ocorre a entrada de água na córnea sob influência da pressão intraocular e do caráter hidrofílico do estroma. Quando a proporção de água no estroma aumenta, ocorre o edema corneano, caracterizado pela separação da malha de colágeno estromal, causando opacidade pela dispersão da luz (SLATTER, 2005; MEEKINS, 2021).

\section{- $\quad$ Ceratites ulcerativas em cães}

\section{- Definição e etiopatogenia}

A ceratite ulcerativa, também denominada úlcera de córnea, é caracterizada pela perda do epitélio corneano, com exposição de porções variáveis do estroma (WHITLEY; HAMOR, 2021). A etiologia é variada, podendo envolver alterações do filme lacrimal, anormalidades de pálpebras ou de cílios, traumas, queimaduras químicas, corpos estranhos e infecções (GALERA et al., 2009; MARTIN DE BUSTAMANTE et al., 2019).

As alterações da produção do filme lacrimal, tanto do componente aquoso quanto do lipídico ou mucoso, podem induzir à síndrome do olho seco. O ressecamento da superfície ocular também pode ocorrer por alterações palpebrais, como no caso de euribléfaro e lagoftalmo; assim como por características orbitárias que levam à exoftalmia (LIN; PETERSEN-JONES, 2007). Lesões em nervos facial e trigêmeo também comprometem a função palpebral e a produção lacrimal, levando ao desenvolvimento do olho seco neurogênico (MAGGS, 2017). Independentemente da causa do olho seco, as consequências associadas são a hipertonicidade do filme lacrimal, desidratação e hipóxia do epitélio corneano; lesão mecânica pela fricção das pálpebras sobre o epitélio; acúmulo de metabólitos potencialmente tóxicos, como ácido lático; e o desenvolvimento de um microambiente propício para a proliferação de microorganismos (LIN; PETERSEN-JONES, 2007). 
A inversão da pálpebra (entrópio), o posicionamento anormal dos cílios (distiquíase, triquíase e cílio ectópico) são condições comuns no cão e podem predispor a formação das úlceras (LIN; PETERSEN-JONES, 2007). As ceratites ulcerativas causadas por estas alterações palpebrais ocorrem primariamente em função do atrito que o cílio ou a pálpebra exerce sobre a superfície corneana, levando à remoção mecânica da barreira epitelial (MAGGS et al., 2017; WHITLEY; HAMOR, 2021).

Os traumas em região corneana podem ocorrer em decorrência de corpos estranhos e de trauma exógeno, e são comuns em cães. Os corpos estranhos podem estar no fórnice conjuntival, retidos na superfície corneana, ou mesmo penetrando em camadas mais profundas da córnea (MAGGS et al., 2017). Os traumas penetrantes também podem ser causados por espinhos, arranhaduras de gato, mordeduras, cirurgias intraoculares (MAGGS et al., 2017; HENDRIX, 2021), e podem causar a laceração corneana parcial ou total, podendo resultar em perda de humor aquoso, colabamento da câmara anterior ou prolapso da íris (WHITLEY; HAMOR, 2021).

Traumas contusos podem causar danos focais ou difusos a qualquer uma ou a todas as camadas da córnea. É importante destacar que os próprios cães podem provocar um auto traumatismo em decorrência de prurido ou dor ocular, causando ampliação ou novo defeito epitelial e predispondo a infecções, e por isso a recomendação de dispositivos que impeçam o auto traumatismo é imperativa em cães com afecção ocular (MAGGS et al., 2017).

As queimaduras químicas geralmente são provocadas por agentes ácidos ou alcalinos, os quais após o contato com a córnea causam perda epitelial imediata (RENWICK; PETERSEN-JONES, 2009). No caso das lesões por ácidos, o efeito tóxico não é progressivo, uma vez que a coagulação proteica no epitélio aprisiona e limita a penetração do ácido. Já os agentes alcalinos ligam-se ao estroma, saponificam as membranas celulares e penetram rapidamente nos tecidos, tornando as queimaduras alcalinas mais graves (WHITLEY; HAMOR, 2021). Alguns autores relataram úlceras de córnea em cães que tiveram contato com produtos de limpeza. Os detergentes não iônicos mostraram-se menos irritantes para os olhos do que os detergentes aniônicos (RENWICK; PETERSEN-JONES, 2009; BATES, 2017).

As ceratites ulcerativas primariamente de origem infecciosa são incomuns em cães, uma vez que a córnea intacta e saudável do cão é altamente resistente à infecção (WHITLEY; HAMOR, 2021). Não foram identificadas bactérias como agentes patogênicos primários de ceratite ulcerativa no cão, e a infecção bacteriana geralmente constitui um fenômeno secundário (MAGGS, 2017; EKAPOPPHAN, 2018). As bactérias que infectam as úlceras corneanas geralmente são as mesmas que fazem parte da microbiota da superfície ocular do cão, como Staphylococcus spp. e Streptococcus spp. e Pseudomonas aeruginosa (MAGGS et al., 2017; HEWITT, 2020).

Com relação aos protozoários, foi descrito um caso de ceratite ulcerativa diretamente associada à Leishmania sp (BRITO et al., 2007). Em cães, a ceratite ulcerativa fúngica é rara, podendo ser vista com maior frequência em humanos e equinos. Os fungos são considerados patógenos oportunistas, principalmente quando há um defeito preexistente no epitélio corneano ou imunossupressão local. A forma mais comum de entrada é por meio de traumas, particularmente, na presença de matéria orgânica vegetal. Os agentes fúngicos já relacionados com as ceratite 
ulcerativas em cães foram Penicillium, Fusarium e Aspergillus (WHITLEY; HAMOR, 2021; TSVETANOVA, 2021).

Outras potenciais causas de ulceração corneana em cães são: ruptura de bolhas epiteliais em córneas edematosas e a erosão epitelial causada por cristais lipídicos ou depósitos de cálcio estromais em pacientes com ceratopatia lipídica ou degeneração calcária da córnea (RENWICK; PETERSEN-JONES, 2009; MAGGS, 2017).

Um tipo muito específico de ulceração corneana é o defeito epitelial corneano espontâneo crônico (DECEC), também denominado úlcera indolente ou úlcera refratária. Estas úlceras são caracterizadas por adesão defeituosa do epitélio ao estroma, devido a falhas na membrana basal e à deficiência de hemidesmossomos e moléculas de adesão entre a membranas basal do epitélio e o estroma corneano, o que dificulta a cicatrização de úlceras superficiais (WHITLEY; HAMOR, 2021).

\section{- Epidemiologia}

Estudos epidemiológicos sobre a ceratite ulcerativa em cães descreveram as características de raça, idade, gênero e alterações clínicas relacionadas à doença (TOLAR et al., 2006; HINDLEY et al., 2016; O'NEILL et al., 2017; MONTEIRO et al., 2018; COSTA et al., 2019). A idade média dos cães acometidos pela ceratite ulcerativa em diferentes estudos variou entre dois a cinco anos (TOLAR et al., 2006), seis anos (HINDLEY et al., 2016), 7,2 anos (O'NEILL et al., 2017), nove anos (MONTEIRO et al., 2018) e cinco a sete anos (COSTA et al., 2019).

Observou-se que cães de raças braquicefálicas podem ser predispostos ao desenvolvimento das úlceras corneanas (TOLAR et al., 2006; HINDLEY et al., 2016; MONTEIRO et al., 2018; COSTA et al., 2019). Dentre 97 cães com ceratite ulcerativa, constatou-se que as raças mais frequentes foram a Pequinês $(26 \%)$, a Shih Tzu $(20 \%)$, a Boston Terrier (11\%) e a Pug (8\%) (TOLAR et al., 2006). Num grupo de 71 cães com ceratite ulcerativa, $25 \%$ de cães eram sem raça definida e $11 \%$ eram Shih Tzu e Pug (HINDLEY et al., 2016). A raça Shih tzu representou 33,33\% dos cães com úlceras de córnea em estudo feito em Cuiabá-Brasil (MONTEIRO et al., 2018). Em outro estudo, os braquicefálicos apresentaram $62 \%$ dos casos, e a raça Shih-tzu foi responsável por $22 \%$ desses cães (COSTA et al., 2019).

Os cães braquicefálicos carecem de muitos mecanismos protetores observados em cães meso e dolicocefálicos. O bulbo ocular pronunciado e a ampla fissura palpebral dos cães braquicefálicos predispõe à exoftalmia e a traumas oculares, além de dificultar o fechamento palpebral normal, levando à lagoftalmia. Adicionalmente, muitos cães braquicefálicos têm triquíase de pregas nasais, entrópio medial ou distiquíase. Qualquer uma destas condições pode iniciar uma ulceração ou dificultar a reepitelização corneana (SLATTER, 2005; WHITLEY; HINDLEY et al., 2016; MONTEIRO et al., 2018; COSTA et al., 2019; WHITLEY; HAMOR, 2021).

Os cães braquicefálicos frequentemente tem uma camada lacrimal lipídica mais delgada e um recobrimento limitado da córnea central pelo filme lacrimal. Além disso, a sensibilidade corneana dos braquicefálicos é menor, quando comparada à sensibilidade dos cães meso e dolicocefálicos (IWASHITA et al., 2020), o que pode alterar negativamente os mecanismos de proteção e predispor a injúrias traumáticas na 
córnea, bem como pode dificultar o reconhecimento, por parte do tutor, de uma úlcera corneana em estágio inicial (TOLAR et al., 2006; HINDLEY et al., 2016).

Além das características raciais, a ceratite ulcerativa também pode estar associada a outros fatores. A uveíte anterior foi a doença ocular concomitante mais comum $(13,2 \%)$, seguida por ceratoconjuntivite seca $(10,5 \%)$, triquíase, distiquíase e cílios ectópicos $(6,1 \%)$, euribléfaro $(5,3 \%)$, ceratite pigmentar $(4,4 \%)$ entrópio de canto medial $(4,4 \%)$, tumor palpebral $(1,8 \%)$ e corpo estranho corneano $(1,8 \%)$ (COSTA et al., 2019).

Em um levantamento, $31 \%$ dos cães com ceratite ulcerativa faziam uso prévio de corticosteróides e $24 \%$ tinham doença da superfície ocular concomitante, principalmente a ceratoconjuntivite seca (HINDLEY et al., 2016). Em outro estudo, observou-se que $29 \%$ dos cães com úlcera de córnea recebiam corticosteroides tópicos ou sistêmicos no momento do diagnóstico, e 54\% tinham ceratoconjuntivite seca. $O$ mesmo estudo constatou que $91 \%$ dos cães com ceratites bacterianas ou eram braquicefálicos, ou tinham olho seco, ou estavam sendo tratados com corticosteróides (TOLAR et al., 2006).

Cães com ceratoconjuntivite seca (CCS) têm uma maior população bacteriana conjuntival, uma vez que as bactérias não são drenadas efetivamente da conjuntiva pelo filme lacrimal. Enzimas antibacterianas que normalmente suprimem a proliferação destes micro-organismos não estão presentes em quantidade normal nos cães com CCS. A baixa produção lacrimal pode causar ulceração corneana e inibir o processo de reepitelização (TOLAR et al., 2006). A administração de corticosteroides tópicos diminui a migração epitelial e o processo de cicatrização. Não há evidência clara da associação do uso de corticosteroide com o início da ceratite ulcerativa. Observações de supressão da cicatrização e da inflamação levaram à hipótese de que o corticosteroide atua contribuindo com a progressão de úlceras corneanas préexistentes (TOLAR et al., 2006).

Entre os estudos epidemiológicos, a distribuição das características clínicas das ceratite ulcerativas foi variável. Em uma investigação, observou-se que $77,9 \%$ das úlceras eram do tipo superficial e $22,10 \%$ eram estromais ou descemetocele ou perfuradas, denominadas úlceras complicadas (MONTEIRO et al., 2018). Hindley et al. (2016) descreveram a ocorrência de 35\% de ceratomálica, 39\% de úlceras com comprometimento menor que $1 / 3$ do estroma corneano, $27 \%$ entre $1 / 3$ e 2/3 do estroma, e $34 \%$ com comprometimento de mais de $2 / 3$ do estroma. Ainda, $73 \%$ das úlceras estavam associadas ao flare aquoso e $40 \%$ das úlceras associadas ao flare concorriam com hipópio. Quanto à localização, 77\% apresentavam-se na córnea central. Em outro estudo, a úlcera corneana foi observada na córnea central em $66 \%$ dos casos (TSVETANOVA et al., 2021). Quanto à profundidade, as úlceras superficiais, estromais e descemetoceles e perfurações foram descritas em $32 \%$, 34\% e $34 \%$ dos casos, respectivamente (IWASHITA et al., 2020). Em outro estudo, 21\% das úlceras eram superficiais, 34\% estromais, 33\% estromais profundas e 13\% eram perfurações (TSVETANOVA et al., 2021). 


\section{- Fisiopatogenia e sinais clínicos}

$\mathrm{Na}$ ceratite ulcerativa superficial, caracterizada pela perda apenas do epitélio, a cicatrização se inicia uma hora após o insulto e ocorre da periferia para o centro por meio do deslizamento das células epiteliais vizinhas; e da camada basal para a camada de células escamosas por meio de mitose. O processo de deslizamento das células epiteliais ao redor da margem da lesão leva, em média, de 48 a 72 horas, e acontece independente do tratamento realizado, podendo ocorrer a recuperação da população de células perdidas em torno de sete dias (GILGER, 2007; GALERA et al., 2009).

Nas ceratites ulcerativas com perda estromal, ocorre deslizamento e mitose das células epiteliais adjacentes à lesão, resultando numa cobertura epitelial de espessura normal, mas isso não é suficiente para restaurar a curvatura corneana. A reposição estromal requer a síntese do colágeno e as conexões entre as fibrilas, síntese de proteoglicanos e remodelamento gradual da ferida. Em uma a duas horas após a lesão estromal ocorre o edema, seguido por um influxo de neutrófilos do filme lacrimal. Os ceratócitos adjacentes ao defeito se transformam em fibroblastos que se proliferam e sintetizam colágeno e outros componentes da matriz extracelular. A atuação contínua destes fibroblastos leva à reposição da espessura do estroma e à recuperação da curvatura corneana. As novas lamelas e fibras colágenas produzidas possuem um arranjo desorganizado e podem resultar em uma cicatriz com opacidade corneana (WHITLEY; HAMOR, 2021).

A regeneração endotelial é limitada, devido à reduzida capacidade mitótica das células endoteliais. Quando há lesão endotelial, estas células exibem suas características de polimorfismo e polimegatismo, ou seja, alteram sua forma e tamanho com o objetivo de preenchimento do defeito endotelial. Em lesões extensas, as células endoteliais podem não conseguir recobrir o defeito, o que culmina em edema corneano permanente (SLATTER, 2005).

O processo de cicatrização das ceratites ulcerativas é complexo e envolve ações integradas de proteinases, fatores de crescimento e citocinas produzidas por células epiteliais, ceratócitos estromais, células inflamatórias e glândulas lacrimais. Podem ocorrer múltiplas interações autócrinas e parácrinas entre células epiteliais, fibroblastos estromais ativados; e ações exócrinas de fatores secretados pelas células da glândula lacrimal (SIVAK; FINI, 2002).

As enzimas proteolíticas e os fatores de crescimento estão envolvidos no processo de reparação tecidual. A manutenção e reparo da matriz extracelular estromal requer um balanço entre sua síntese, degradação e remodelação. As enzimas proteolíticas têm papel importante na degradação e remodelação da matriz extracelular estromal, e sua ação é controlada por inibidores de proteinases naturais existentes no filme pré-corneal e córnea, a exemplo do inibidor de proteinase $\langle-1,\langle 2-$ macroglobulina e inibidores de metaloproteinases (GOGOVA et al., 2020; WHITLEY; HAMOR, 2021).

A progressão da ceratite ulcerativa ocorre secundariamente à degradação patológica do colágeno corneano estromal e dos proteoglicanos, quando o equilíbrio entre as proteinases e os inibidores da proteinase favorece as proteinases. $E$ o processo onde ocorre a rápida degradação do estroma corneano associada a algumas úlceras corneanas graves é causado por enzimas proteolíticas atuando no colágeno, 
proteoglicanos e outros componentes da matriz extracelular estromal, e é denominado como ceratomalácia ou melting corneano (GILGER, 2007; GUYONNET et al., 2020).

O filme lacrimal, os micro-organismos, as células inflamatórias, as células epiteliais e os fibroblastos produzem e liberam enzimas proteolíticas. As proteinases endógenas são as produzidas por células do próprio indivíduo e as proteases exógenas são as secretadas por organismos infecciosos (HODGES; DARTT, 2013). Exemplos de proteases exógenas incluem as produzidas pela Pseudomonas aeruginosa, como a protease alcalina, elastase A e B, protease IV e elastase modificada (WHITLEY; HAMOR, 2021).

Em córneas lesionadas, a atividade da proteinase aumenta no filme lacrimal. Em cães com ceratite ulcerativa traumática os níveis de MMP-9 no FLP aumentam em comparação com cães clinicamente normais. Se houver infecção, as proteinases secretadas pelos micro-organismos contribuem ainda mais para danos causados à córnea. Em cães com ceratite ulcerativa por $P$. aeruginosa, as concentrações de MMP. 2 e MMP-9 no FLP aumentaram em comparação a cães clinicamente normais (WANG et al., 2008; FARGHALI et al., 2021).

No caso específico do defeito epitelial corneano espontâneo crônico (DECEC) ou úlcera indolente, a supra regulação de metaloproteinases foi postulada como uma causa da deficiência da membrana basal, o que impede a aderência do epitélio ao estroma. Por este motivo a úlcera indolente exibe uma aparência típica caracterizada por um halo de epitélio solto ao redor da úlcera superficial (WHITLEY; HAMOR, 2021).

O edema corneano é uma alteração que acompanha a ceratite ulcerativa, e corresponde ao excesso de fluido que se acumula no interior do estroma, pois a água possui afinidade pelos componentes da matriz extracelular. Nesse caso, ocorre desorganização das lamelas colágenas, implicando em perda da transparência, que pode ser focal ou difusa (SLATTER, 2005; GALERA et al., 2009; WHITLEY; HAMOR, 2021). Em caso de lesão endotelial, haverá comprometimento da função das bombas de $\mathrm{Na}+\mathrm{K}+\mathrm{e}$, consequentemente, a piora do edema corneano (HERRERA, 2008).

A neovascularização do estroma da córnea é uma resposta inespecífica à lesão ou inflamação da córnea. Qualquer insulto que induza a inflamação ou hipóxia pode resultar em angiogênese da córnea (WHITLEY; HAMOR, 2021). A vascularização corneana que pode ser observada em olhos com ceratite ulcerativa é benéfica, pois carreia suprimento sanguíneo para auxiliar a cicatrização. Uma desvantagem é que a presença dos vasos sanguíneos resulta em diminuição da transparência corneana e favorece migração de pigmento para o estroma da córnea (SLATTER, 2005; GALERA et al., 2009).

$\mathrm{Na}$ ceratite ulcerativa, a vascularização corneana pode se apresentar de forma superficial ou profunda. A vascularização superficial ocorre no terço anterior do estroma, geralmente apresenta vasos vermelhos vivos, ramificados e contínuos e são originários da circulação conjuntival do limbo. A vascularização profunda apresenta-se no estroma profundo, por meio da infiltração de vasos contínuos com a circulação ciliar que desaparecem no limbo, além de se apresentarem com coloração vermelho-escura e serem mais retilíneos. A profundidade da lesão corneana primária pode ser indicada pela profundidade dos vasos invasores (SLATTER, 2005; GALERA et al., 2009). A 
vascularização superficial se apresenta em decorrência de processos na superfície corneana (ceratites superficiais), enquanto a profunda ocorre em processos envolvendo o estroma profundo (HERRERA, 2008).

A exposição estromal e de sua densa inervação, além de causar intensa dor, também deflagra o reflexo do axônio quando estimulados (SLATTER, 2005; SLATTER; DIETRICH, 2007). Os mediadores humorais envolvidos com este reflexo do axônio parecem ser prostaglandinas, histamina, acetilcolina e substância $P$, e resultam nos sinais clínicos de uveíte anterior associada à ceratite ulcerativa, denominada uveíte reflexa, caracterizada por miose, hiperemia ocular, blefarospasmo e flare aquoso (GUM et al., 2021).

Isto posto, compreende-se que os sinais clínicos mais comumente encontrados nas ceratites ulcerativas incluem blefaroespasmo, fotofobia, lacrimejamento, secreção e hiperemia conjuntival, perda de transparência, edema e neovascularização da córnea e sinais de uveíte secundária (RADZIEJEWSKI et al., 2018; GUM et al., 2021).

\section{- Diagnóstico e classificação das ceratites ulcerativas}

O diagnóstico da ceratite ulcerativa é feito com base nos sinais clínicos e na retenção do corante de fluoresceína pelo estroma corneano (HEIDI et al., 2013). Durante a anamnese, é importante investigar a possível causa da lesão, o tempo de progressão e a resposta a tratamento prévio. O exame oftalmológico poderá contribuir para a investigação etiológica, por meio de cuidadosa inspeção da pálpebra e conjuntiva e pela avaliação da produção lacrimal (OLLIVIER, 2003).

A fluoresceína sódica é um corante solúvel em água, utilizado na forma de colírio a $2 \%$ ou em tiras de papel impregnadas. Por ser hidrossolúvel, a fluoresceína se dissolve na porção aquosa da lágrima e se adere ao estroma desprotegido de barreira epitelial. A afinidade estromal pela fluoresceína se deve à presença de proteoglicanos na sua matriz extracelular. Quando ocorre a adesão ao estroma, a área corada pela fluoresceína é facilmente detectada por se apresentar com coloração esverdeada e fluorescente, especialmente quando observada utilizando-se de fonte de luz simples ou com filtro azul-cobalto. Deve-se dar preferência ao uso do corante em fitas ao invés do colírio, pois a solução de fluoresceína constitui em excelente meio de cultura para bactérias como a Pseudomonas aeruginosa (MILLER, 2017).

A inspeção da córnea utilizando-se de magnificação auxilia na identificação de edema, vascularização, infiltração inflamatória e pigmentação corneanas. Além disso a avaliação corneana sob magnificação é muito importante para a avaliação da profundidade da ceratite ulcerativa, e permitirá a classificação da úlcera em superficial, estromal e descemetocele, o que terá influência direta na definição pelo tratamento clínico ou cirúrgico (HEIDI et al., 2013).

A ceratite ulcerativa superficial (Figura 3A) é caracterizada pela perda do epitélio da córnea com a exposição do estroma anterior. Estas úlceras geralmente cursam com dor ocular mais intensa que as ceratites ulcerativas mais profundas, em função da maior densidade de inervação do estroma anterior. Por serem superficiais, não promovem alteração visível na curvatura corneana e, por isso, torna-se imprescindível a utilização da fluoresceína para sua identificação (SLATTER, 2005; 
HEIDI et al., 2013). As ceratites ulcerativas superficiais geralmente se resolvem de forma espontânea entre dois a sete dias, desde que não ocorra complicações relacionadas à infecção bacteriana secundária, ao desequilíbrio entre as proteases e seus inibidores, ao defeito epitelial corneano espontâneo crônico/úlcera indolente (Figura 3B) (SLATTER, 2005; BELKNAP, 2015).

A úlcera estromal é caracterizada pela perda do epitélio e de diferentes porções do estroma, podendo envolver desde o estroma anterior (Figura 3C) até o estroma profundo (Figura 3D). Normalmente a ceratite ulcerativa estromal é uma progressão da úlcera superficial é resultado de infecção bacteriana secundária, principalmente Pseudomonas aeruginosa e Streptococcos sp., que contribuem com a produção de proteases. Nas úlceras estromais, a alteração da curvatura corneana fica mais evidente devido ao defeito tecidual. Apesar da úlcera estromal não cursar com a mesma dor quanto à superficial, ela é considerada mais grave devido à maior perda em espessura corneana (SLATTER, 2005; HEIDI et al., 2013).

As úlceras estromais podem evoluir para o quadro de ceratomalácia, também conhecido como úlceras em melting (Figura 3E). Essa evolução, mais frequente em raças braquicefálicas (ABREU et al., 2017), caracteriza-se pela progressiva dissolução do estroma corneano pelas enzimas proteolíticas que atuam sobre o colágeno, proteoglicanos e outros componentes da matriz celular (MAGGS, 2017). Com a ceratomalácia, o estroma corneano assume uma aparência gelatinosa e pode estar projetado anteriormente, além de seu limite anatômico (WHITLEY; HAMOR, 2021).

A descemetocele (Figura 3F) é uma lesão profunda da córnea na qual houve perda do epitélio da córnea e do estroma em toda sua profundidade, levando à exposição da membrana de Descemet. Dessa forma, no local do defeito, há apenas o revestimento pela Descemet e endotélio (WHITLEY; HAMOR, 2021). A membrana de Descemet é uma membrana resistente e elástica, mas tem apenas 3 a $12 \mu \mathrm{m}$ de espessura e, portanto, se rompe facilmente, por isso a descemetocele caracteriza-se pela iminência de perfuração corneana (HEIDI et al., 2013). Uma vez que essa barreira final é rompida, fica caracterizada a lesão de espessura total ou perfuração corneana, com perda do humor aquoso, redução da câmara anterior e do diâmetro pupilar, podendo ocasionar sinéquia anterior, prolapso da íris e seclusão pupilar. Perfurações corneanas não tratáveis, podem evoluir para endoftalmite e perda total da visão (AMORIM et al., 2018).

À inspeção, a descemetocele pode se apresentar como uma fina membrana de aspecto escurecido no fundo do defeito corneano, ou como uma bolha projetada para o meio externo devido à pressão intraocular (SLATTER, 2005). A característica hidrofóbica da membrana de Descemet não permite que ocorra impregnação dessa camada pela fluoresceína, o que auxilia no reconhecimento dessa condição clínica durante o exame oftalmológico, pois a parede da úlcera fica corada devido à presença de estroma, mas o centro não, devido à exposição da membrana de Descemet (SAMPAIO et al., 2017). 
FIGURA 3. Diferentes tipos de ceratites ulcerativas em cães. (A) Úlcera corneana superficial impregnada pela fluoresceína. (B) Defeito epitelial corneano espontâneo crônico ou úlcera indolente. Observar o epitélio de solto (cabeça de seta). (C) Úlcera com comprometimento do estroma anterior, corada pela fluoresceína. Vascularização estromal superficial (cabeça de seta) e edema corneano discreto (asterisco). (D) Úlcera corneana estromal profunda corada pela fluoresceína. Observar a turbidez do humor aquoso em câmara anterior (flare aquoso). (E) Ceratomalácia ou melting corneano. Observar o aspecto gelatinoso do estroma corneano, corado pela fluoresceína. Edema corneano perilesional (asterisco). (F) Exposição da membrana de Descemet. Observar a impregnação da fluoresceína nas paredes da úlcera, mas não no leito da lesão. Vascularização estromal profunda (asterisco) e hipópio (cabeça de seta).
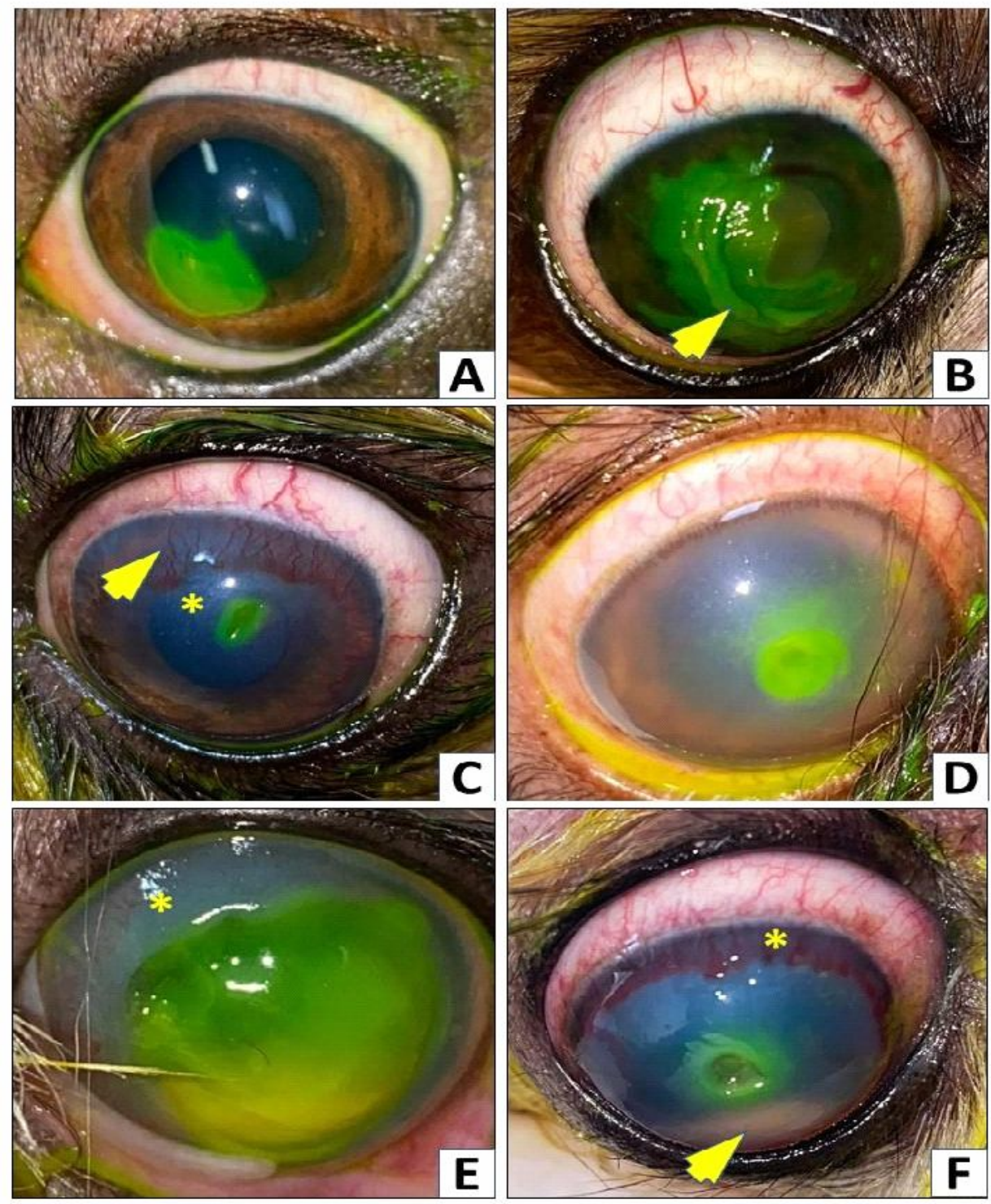

Fonte: Arquivo pessoal da autora Thaissa Vaz Lobo (2021). 


\section{CONSIDERAÇÕES FINAIS}

As ceratites ulcerativas em cães são enfermidades de alta incidência, as quais podem ocasionar sintomas leves como desconforto ocular até a perda da visão. $O$ estudo das estruturas e mecanismos envolvidos no desenvolvimento da úlcera corneana gera uma melhor compreensão da fisiopatogenia e da manifestação clínica da enfermidade, facilitando o diagnóstico pelo médico veterinário. O diagnóstico e a classificação das ceratites ulcerativas são fatores determinantes para a escolha pelo tratamento mais adequado da úlcera de córnea, que pode variar entre protocolos clínicos com colírios, medicamentos de uso sistêmico e diferentes técnicas cirúrgicas. Este trabalho contribui sobremaneira para o veterinário, considerando a importância do diagnóstico precoce como o primeiro passo para a melhor tomada de decisão frente a um cão com ceratite ulcerativa, o que é crucial para evitar a cegueira ou a perda do bulbo ocular.

\section{AGRADECIMENTOS}

Os autores agradecem à Profa. Dra. Marina Pacheco Miguel (IPTSP/UFG), à Universidade Federal de Goiás (UFG), à Escola de Veterinária e Zootecnia (EVZ), ao Programa de Pós-Graduação em Ciência Animal (PPGCA) e ao Conselho Nacional de Desenvolvimento Científico e Tecnológico (CNPq).

\section{REFERÊNCIAS}

ABREU, W.U.; PHILIPPSEN, C.; LIMA, D.J.D.S. Ceratoplastia com recobrimento de terceira pálpebra em felino doméstico para o tratamento de descemetocele com perfuração de córnea. Acta Scientiae Veterinariae, v. 45, p. 1-4, 2017. Disponível em: <https://doi.org/10.22456/1679-9216.85748>. DOI: 10.22456/1679-9216.8574

AMORIM, T.M., RIBEIRO, A.P., RUIZ, T., DOWER, N.M.B., MADRUGA, G., SCHRODER, D.C., et al. Impacto do grau de uveíte em diferentes tipos de úlceras de córneas em cães submetidos ao enxerto pediculado de conjuntiva bulbar - 34 casos. Arquivo Brasileiro de Medicina Veterinária e Zootecnia, Belo Horizonte, v. 70, n. 4, p. 1233-1239, Aug/2018. Disponível em: <https://doi.org/10.1590/1678-41629290.>. DOI: $10.1590 / 1678-4162-9290$

ANDRADE, A. L. Semiologia do sistema visual dos animais domésticos. In: FEITOSA, F.L.F. Semiologia veterinária - A Arte do Diagnóstico. São Paulo: Roca, 2020.

BATES, N. Risks from detergent exposure. Companion Animal, v. 22, n. 2, p. 93-97, 2017. Disponível em: <https://doi.org/10.12968/coan.2017.22.2.93>. DOI: 10.12968/coan.2017.22.2.93

BELKNAP, E.B.. Corneal Emergencies. Topics In Companion Animal Medicine, v. 30, n. 3, p. 74-80, 2015. Disponível em:<https://doi.org/10.1053/j.tcam.2015.07.006>. DOI: 10.1053/j.tcam.2015.07.006 
BENTLEY, E. Spontaneous chronic corneal epithelial defects in dogs: a review. Journal of the American Animal Hospital Association, v. 41, n. 3, p. 158-165, 2005. Disponível em: <https://doi.org/10.5326/0410158>. DOI: 10.5326/0410158

BRITO, F. L. C.; ALVES, L.C; MAIA, F.C.L; ALBUQUERQUE, A.R.;ORTIZ, J.O.D.; LAUS, J.L. Amastigota forms resembling Leishmania sp. on corneal ulceration in a dog: case report. Arquivo Brasileiro de Medicina Veterinária e Zootecnia, Belo Horizonte, v. 59, n. 1, p.81-84, Feb/ 2007. Disponível em: <https://doi.org/10.1590/S010209352007000100014>.DOI:10.1590/S0102-09352007000100014.

COSTA, D.; LEIVA, M.; SANZ,F.; ESPEJO, V.; ESTEBAN, J.; VERGARA, J., et al. A multicenter retrospective study on cryopreserved amniotic membrane transplantation for the treatment of complicated corneal ulcers in the dog. Veterinary Ophthalmology. v. 22, n. 5, p. 695-702, 2019. Disponível em: <https://doi.org/10.1111/vop.12643>.DOI:10.1111/vop.12643014.

EKAPOPPHAN, D; SRISUTTHAKARN, A; MOONARMART, W; BUDDHIRONGAWATR, $\mathrm{R}$; BANGPHOOMI, N. Identification and antimicrobial susceptibility of microorganisms isolated from severe corneal ulcers of dogs in Thailand. The Journal of Veterinary Medical Science, v. 80, n. 8, p. 1259-1265, 2018.Disponível em:<https://doi.org/10.1292/jvms.180045>. DOI:10.1292/jvms.18-0045

FARGHALI, H. A.; ABDELKADER, N. A.; ABUBAKR, H. O.; RAMADAN, E. S.; KHATTAB, M. S.;SALEM, N. Y.; EMAM, I. A. Corneal Ulcer in Dogs and Cats: Novel Clinical Application of Regenerative Therapy Using Subconjunctival Injection of Autologous Platelet-Rich Plasma. Frontiers in Veterinary Science, v. 8, 2021. Disponívelem:<https://doi.org/10.3389/fvets.2021.641265>.DOI:10.3389/fvets.2021.641 2655

FEATHERSTONE, H.J; HEINRICH, C.L. Ophthalmic Examination and Diagnostics. In: GELATT, K. N.; BEN-SHLOMO, G.; GILGER, B. C.; HENDRIX, D. V.; KERN, T. J.; PLUMMER, C. E..Veterinary Ophthalmology(6. ed). John Wiley \& Sons, p.564-578, 2021.

GALERA P.D.; LAUS, J.L.; ORIÁ, A.P. Afecções da túnica fibrosa. In: Laus, J.L. Oftalmologia Clínica e Cirúrgica em Cães e em Gatos. 1ㄹa ed. São Paulo. Roca. p.6992. 2009

GILGER, B.C. Diseases and surgery of the canine cornea. In: GELATT K.N. Veterinary Ophthalmology. 4. ed. Oxford: Blackwell Publishing, p.690-752, 2007.

GOGOVA,S.; LEIVA, M.; ORTILLES, A.; LACERDA, R.P.; SERUCA,C.; LAGUNA, F., corneal defects in dogs: A multicentric retrospective study of 100 cases (2012-2018) Veterinary ophthalmology, v.23, n. 3 p. 450-459, 2020. Disponível em:<https://doi.org/10.1111/vop.12740>. DOI:10.1111/vop.12740 
GUM, G.G.; HENDRIX, D.V.H.; THOMASY, S.M. Physiology of the Eye. In: GELATT, K. N.; BEN-SHLOMO, G.; GILGER, B. C.; HENDRIX, D. V.; KERN, T. J.; PLUMMER, C. E..Veterinary Ophthalmology(6. ed). John Wiley \& Sons, p.124-167, 2021.

GUYONNET, A.; DESQUILBET, L.; FAURE, J.; BOURGUET, A.; DONZEL, E.; CHAHORY, S. Outcome of medical therapy for keratomalacia in dogs. Journal of Small Animal Practice, v. 61, n. 4, p. 253-258, $2020 . \quad$ Disponível em:<https://doi.org/10.1111/jsap.13118>. DOI:10.1111/jsap.13118

HENDRIX, D.V.H. Diseases and surgery of the canine anterior uvea. In: GELATT, K. N.; BEN-SHLOMO, G.; GILGER, B. C.; HENDRIX, D. V.; KERN, T. J.; PLUMMER, C. E..Veterinary Ophthalmology(6. ed). John Wiley \& Sons, p.1259-1316, 2021.

HERRERA, D. Afecções da córnea. In: HERRERA, D. Oftalmologia Clínica em Animais de Companhia. São Paulo: MedVet, p. 111-140. 2008.

HEWITT, J. S.; ALLBAUGH, R. A.; KENNE, D. E.; SEBBAG, L. Prevalence and antibiotic susceptibility of bacterial isolates from dogs with ulcerative keratitis in Midwestern United States. Frontiers in Veterinary Science, v. 7, p. 912, 2020. Disponível DOI:10.3389/fvets.2020.583965 em:<https://doi.org/10.3389/fvets.2020.583965>.

HINDLEY, K.E., GROTH, A.D., KING, M., GRAHAM, K. AND BILLSON, F.M. Bacterial isolates, antimicrobial susceptibility, and clinical characteristics of bacterial keratitis in dogs presenting to referral practice in Australia. Veterinary ophthalmology, v. 19, n. 5, p. 418-426, 2016. Disponível em:<https://doi.org/10.1111/vop.12325>. DOI:10.1111/vop.12325

HODGES, R. R.; DARTT, D. A. Tear film mucins: front line defenders of the ocular surface; comparison with airway and gastrointestinal tract mucins. Experimental eye research, $\quad$ v. 117, p. $62-78, \quad 2013 . \quad$ Disponível em:<https://doi.org/10.1016/j.exer.2013.07.027>. DOI:10.1016/j.exer.2013.07.027

IWASHITA, H, WAKAIKI, S, KAZAMA, Y, SAITO, A. Breed prevalence of canine ulcerative keratitis according to depth of corneal involvement. Veterinary Ophthalmology, v. 23, n. 5, p. 849-855, 2020 Disponível em:<https://doi.org/10.1111/vop.12808>. DOI:10.1111/vop.12808

KIERSZENBAUM, A.; TRES, L. Sensory organs: vision and hearing. In KIERSZENBAUM, Abraham L.; TRES, Laura. Histology and cell biology: an introduction to pathology (5 ed.). Philadelphia: Elsevier Health Sciences, p 300-341, 2019.

LIN, C.T.; PETERSEN JONES, S. M. Antibiotic susceptibility of bacterial isolates from corneal ulcers of dogs in Taiwan. Journal of small animal practice, v. 48, n. 5, p. 271- 
274, 2007. Disponível em:<https://doi.org/10.1111/j.1748-5827.2007.00348.x>. DOI:10.1111/j.1748-5827.2007.00348.x

MAGGS, D.; MILLER, P.; OFRI, R.; Slatter's Fundamentals of Veterinary Ophthalmology E-Book. Elsevier Health Sciences, 2017.

MAGGS, D.J. Cornea and Sclera. In: MAGGS, D.; MILLER, P.; OFRI, R.; Slatter's Fundamentals of Veterinary Ophthalmology E-Book. Elsevier Health Sciences,p. 184-219, 2017.

MARTIN DE BUSTAMANTE, M. G.; GOOD, K. L.; LEONARD, B. C.; HOLLINGSWORTH, S. R.; EDWARDS, S. G.; KNICKELBEIN, K. E; et al. Medical management of deep ulcerative keratitis in cats: 13 cases. Journal of feline medicine and surgery, v. 21, n. 4, p. 387-393, 2019. Disponível em:<https://doi.org/10.1177/1098612X18770514>. DOI:10.1177/1098612X18770514

MAZZI, M. F.; DIAS, M. D. A. Ceratite ulcerativa corneana traumática em cão: tratamento com oxigenoterapia hiperbárica. PUBVET, v. 12, p. 136, 2018. Disponível em:<https://doi.org/10.31533/pubvet.v12n12a226.1-

8>.DOI:10.31533/pubvet.v12n12a226.1-8

MEEKINS, J. M.; RANKIN A.J.; SAMUELSON, D.A. Ophthalmic Anatomy. In: GELATT, K. N.; BEN-SHLOMO, G.; GILGER, B. C.; HENDRIX, D. V.; KERN, T. J.; PLUMMER, C. E..Veterinary Ophthalmology(6. ed). John Wiley \& Sons, p. 41-123, 2021.

MILLER, P.E. The Eye and Vision. In D.J. Maggs, P.E. Miller \& R. Ofri, Slatter's Fundamentals of Veterinary Ophthalmology E-Book. Elsevier Health Sciences, 2017.

MONTEIRO, G. B.; RUIZ, T.; SCHRODER, D. C.; SILVEIRA, M. M.; DOWER, N.; KAGUEYAMA, F.; et al. Antibiotic susceptibility of bacteria isolated from different types of ulcerative keratitis of dogs in the city of Cuiabá, Brazil. Pesquisa Veterinária Brasileira, v. 38, n. 4, p.726-733, 2018. Disponível em:<http://dx.doi.org/10.1590/16785150-pvb-4906.>. DOI:10.1590/1678-5150-pvb-4906

MURPHY, C.; GUTIERREZ, J. The Eye. In: HERMANSON, J.W; DELAHUNTA, A; EVANS, H.E. Miller's anatomy of the dog. (5 ed) Missouri: Elsevier Saunders, p. 858$891,2019$.

OLLIVIER, F. J. Bacterial corneal diseases in dogs and cats. Clinical techniques in small animal practice, v. 18, n. 3, p. 193-198, 2003. Disponível em:<https://doi.org/10.1016/s1096-2867(03)90016-8>.DOI:10.1016/s1096-

2867(03)90016-8

O'NEILL, D. G.; LEE, M. M.; BRODBELT, D. C.; CHURCH, D. B.; SANCHEZ, R. F. Corneal ulcerative disease in dogs under primary veterinary care in England: 
epidemiology and clinical management. Canine Genetics and Epidemiology, v. 4, n. 1, p. 1-12, 2017. Disponível em:<https://doi.org/10.1186/s40575-017-0045-5>. DOI:10.1186/s40575-017-0045-5

RADZIEJEWSKI, K.; BALICKI, I.; SZADKOWSKI, M. Assessment of corneal and conjunctival metaplasia by impression cytology during the treatment of canine keratoconjunctivitis sicca. Acta Veterinaria Hungarica, v. 66, n. 2, p. 189-203, 2018. Disponível em:<https://doi.org/10.1556/004.2018.018>. DOI:10.1556/004.2018.018

RENWICK, P.W.; PETERSEN-JONES, S. Orbital and ocular pain. In: PEIFFER, R.L.; PETERSEN-JONES, S. Small animal ophthalmology: a problem-oriented approach. (4ed). London: Saunders Elsevier. 2009.

SAMUELSON, D.A. Ophthalmic Anatomy. In: GELATT, K. N.; GILGER, B. C.; KERN, T. J. Veterinary Ophthalmology(5. ed). John Wiley \& Sons, p. 39-170, 2013.

SLATTER, D. H. Córnea e esclera. In: SLATTER, D. H. Fundamentos de oftalmologia veterinária. (4aa ed). São Paulo: Roca, p.283-338, 2005.

SLATTER, D.H.; DIETRICH, U. Córnea e esclera. In: SLATTER, D.H. Manual de cirurgia de pequenos animais. (3를 ed). v.2, Barueri: Manole, p.1368- 1396, 2007.

SIVAK, J. M.; FINI, M. E. MMPs in the eye: emerging roles for matrix metalloproteinases in ocular physiology. Progress in retinal and eye research, v. 21, n. 1, p. 1-14, 2002. Disponível em: <https://doi.org/10.1016/S1350-9462(01)00015-5>.DOI:10.1016/S13509462(01)00015-5

TOLAR, E. L.; HENDRIX, D. V.; ROHRBACH, B. W.; PLUMMER, C. E.; BROOKS, D. E.; GELATT, K. N. Evaluation of clinical characteristics and bacterial isolates in dogs with bacterial keratitis: 97 cases (1993-2003). Journal of the American Veterinary Medical Association, v. 228, n. 1, p. 80-85, 2006. Disponível em: <https://doi.org/10.2460/javma.228.1.80>. DOI:10.2460/javma.228.1.80

TSVetANOVA, A., POWELL, R. M., TSVETANOV, K. A., SMITH, K. M., GOULD, D. J. Melting corneal ulcers (keratomalacia) in dogs: A 5year clinical and microbiological study (2014-2018). Veterinary Ophthalmology, 2021. Disponível em: <https://doi.org/10.1111/vop.12885>. DOI:10.1111/vop.12885

TURNER, S.M. Oftalmologia em pequenos animais. Rio de Janeiro: Elsevier, p.370, 2010.

WANG, L.; PAN, Q.; ZHANG, L.; XUE, Q; CUI, J.; QI, C. Investigation of bacterial microorganisms in the conjunctival sac of clinically normal dogs and dogs with ulcerative keratitis in Beijing, China. Veterinary ophthalmology, v. 11, n. 3, p. 145-149, 2008. Disponível em: < https://doi.org/10.1111/j.1463-5224.2008.00579.x >. DOI:10.1111/j.1463-5224.2008.00579.x 
WHITLEY, R.D; HAMOR, R.E. Diseases and Surgery of the Canine Cornea and Sclera In: GELATT, K. N.; BEN-SHLOMO, G.; GILGER, B. C.; HENDRIX, D. V.; KERN, T. J.; PLUMMER, C. E.. Veterinary Ophthalmology (6.ed). John Wiley \& Sons. p.1082-1172, 2021. 